Article

\title{
The Effect of Biomass Pellet Length, Test Conditions and Torrefaction on Mechanical Durability Characteristics According to ISO Standard 17831-1
}

\author{
Hamid Gilvari ${ }^{1, *(\mathbb{D})}$, Wiebren De Jong ${ }^{2}$ and Dingena L. Schott ${ }^{1}$ \\ 1 Department of Maritime and Transport Technology, Section of Transport Engineering and Logistics, \\ Faculty of Mechanical, Maritime and Materials Engineering, Delft University of Technology, \\ 2628 CD Delft, The Netherlands; D.L.Schott@tudelft.nl \\ 2 Department of Process and Energy, Section of Large Scale Energy Storage, Faculty of Mechanical, \\ Maritime and Materials Engineering, Delft University of Technology, 2628 CB Delft, The Netherlands; \\ Wiebren.deJong@tudelft.nl \\ * Correspondence: h.gilvari@tudelft.nl; Tel.: +31-15-27-83130
}

Received: 8 May 2020; Accepted: 9 June 2020; Published: 11 June 2020

check for updates

\begin{abstract}
With the recent increase in biomass pellet consumption, the mechanical degradation of pellets during transport and handling has become more important. ISO standard 17831-1 is an accepted global standard that is commonly used amongst researchers and industries to determine the mechanical durability of pellets. However, the measured mechanical durability sometimes fails to match the certificate accompanying the shipment. In such cases, pellet length specifications are suspected to play a role. This paper studies the effect of pellet length on mechanical durability for various types of commercially produced biomass pellets. In addition, the effect of test conditions and torrefaction on the mechanical durability of biomass pellets has been investigated. To study the effect of pellet length, pellets were classified into three groups: shorter than $15 \mathrm{~mm}, 15$ to $30 \mathrm{~mm}$, and longer than $30 \mathrm{~mm}$, and their length distributions were measured using an in-house image processing tool. Then, the mechanical durability of pellets was measured using ISO standard 17831-1. The mechanical durability results were compared to random-sized pellet samples. To study the effect of test conditions, the mechanical durability test was operated at different time intervals to elucidate the effect of tumbling at different conditions. The results show that the mechanical durability depends highly on the length distribution of the pellets, with a difference between categories of up to $13 \%$. It was also observed that the mechanical durability remains relatively constant after a specific time interval. Based on the results, we highly recommend modifying the current ISO standard to account for the pellet length distribution (PLD).
\end{abstract}

Keywords: biomass pellet; mechanical durability; ISO standard 17831-1; pellet length distribution; image processing

\section{Introduction}

Biomass pellets show great potential as a renewable energy carrier for replacing fossil fuels in the near future. According to the Bioenergy Europe statistical report 2019 [1], the worldwide production of biomass pellets was around 32 million tonnes in 2017, of which Europe, a net consumer, used more than 24 million tonnes. Biomass pellets are mostly imported into the EU from the USA and Canada [1]. Despite the huge international pellet trade, the market faces many challenges in terms of transportation, handling and storage, in particular due to the high fines content and dust generation throughout the supply chain. For instance, there have been many fatal accidents caused by dust explosions [2]. 
The amount of fines and dust generated during transport and handling is linked to the pellet strength, which in turn depends on the material origin, pre-treatment processes, and the densification process [3]. According to ISO standard 16,559 [4], mechanical durability is defined as "the ability of densified biofuels units (e.g., briquettes, pellets) to remain intact during loading, unloading, feeding, and transport". Note that mechanical durability is not the same as pellet strength: while pellet strength is an inherent property of the biomass pellet and is directly linked to the aforementioned parameters, mechanical durability depends on the test and operational handling conditions. The material origin, pre-treatment processes and densification process specifications affect the pellet strength but, once the pellets have been made, the effect of these remains constant. The amount of fines and dust generated during transportation and handling is normally measured in the laboratory, for example using mechanical durability testers [5]. One such mechanical durability tester, defined by ISO 17831-1 [6], is the tumbling can method, which is commonly used for industrial and research purposes [7-15].

The higher the mechanical durability of the pellets, the lower the fines content and dust generation during transport and handling. National and regional standards have been introduced to classify biomass pellets based on their physicochemical properties [16-20]. ISO standard 17225-2 [21] is an international standard for the classification of biomass pellets based on their mechanical durability values, namely DU97.5 and DU96.5, which represent a mechanical durability of more than $97.5 \%$ and $96.5 \%$ respectively. However, there is as yet no direct and clear link between the laboratory tests and real conditions regarding the amount of fines and dust generated during large-scale transportation, even for pellets of known mechanical durability.

Research has been carried out to correlate mechanical durability with other physical properties. Larsson and Samuelsson [22] compared the results of ISO standard 17831-1 with those of Ligno single pellet durability and found a good correlation $\left(R^{2}=0.94\right)$, although they found almost no correlation between the compressive strength of individual pellets and the mechanical durability. Temmerman et al. [5] found no correlation between the mechanical durability and pellet density. Williams et al. [23] compared the mechanical durability of six different types of commercial biomass pellets with their required milling energies $\left(\mathrm{kWh} \cdot \mathrm{t}^{-1}\right)$ and the material grindability and found a good correlation between milling energy and mechanical durability $\left(R^{2}>0.92\right)$. However, they only found a high correlation between mechanical durability and grindability for pellets with a mechanical durability (based on ISO standard 17831-1 [6].) of higher than $97 \%\left(R^{2}>0.994\right)$.

The relationship between mechanical durability and the pellet length has been reported in two papers, to the best of the author's knowledge. Chico-Santamarta et al. [24] simultaneously studied the effect of pellet length and storage duration on the mechanical durability of canola pellets with the length between $15-25 \mathrm{~mm}$. They measured the length of 50 randomly chosen pellets from different batches. Because the effect of particle length was not isolated from the effect of storage duration, a correlation between the length and mechanical durability could not be established. In the other study, Serrano et al. [25] measured the length of just 15 randomly chosen pellets from different batches of barley straw pellets. They found that the mechanical durability increases by increasing the average pellet length. However, the correlation has not been quantified.

As biomass pellets become increasingly popular, research into the pre-treatment processes is continuing to enhance the material properties. Torrefaction is one such process, and involves roasting the material at a temperature of $200-300^{\circ} \mathrm{C}$ in the absence of oxygen to reduce the moisture content and the volatile matter [26]. Torrefied biomass pellets have a higher bulk and energy density and increased hydrophobicity [27]. Due to the partial removal of the natural plasticizing agents such as lignin and hydroxyl groups during the torrefaction process, the resulting pelletized materials are however more fragile $[28,29]$. Larsson et al. [30] showed that torrefaction temperature and moisture content may affect the mechanical strength of pilot-scale produced Norway spruce. They torrefied the materials at a temperature of $270-300{ }^{\circ} \mathrm{C}$ and produced pellets by addition of moisture at the two levels of 11 and $15 \%$, while the die temperature was an uncontrolled variable. The resulting mechanical durability was between 80.4 and $90.3 \%$. Rudolfsson et al. [29] concluded that the degree of torrefaction has a complex 
effect on pellet quality parameters such as mechanical durability for the pilot-scale produced torrefied Scots pine. This effect is not yet fully understood and none of the above studies have addressed the relationship between mechanical durability and pellet length.

The primary goal of this paper is to evaluate the influence of the pellet length distribution (PLD) on the mechanical durability results obtained from ISO standard 17831-1 [6]. We tested a range of materials, including white and torrefied pellets, to study the effect of torrefaction on mechanical durability. The findings contribute to a better understanding of the breakage behaviour and, consequently, the mechanism of fines and dust generation during a mechanical durability test.

\section{Materials and Methods}

\subsection{Materials}

Five different types of biomass pellets with varying origins and produced under different conditions were used in this study. These were torrefied mixed wood, torrefied poplar, raw and torrefied Miscanthus, and sawdust pellets. The Miscanthus was first pelletized and then torrefied at a temperature of $270{ }^{\circ} \mathrm{C}$ for $45 \mathrm{~min}$, during which it lost around $20 \%$ of its initial mass. The poplar was torrefied at $285^{\circ} \mathrm{C}$ for around $45 \mathrm{~min}$ with a mass loss of $25 \%$. No information was disclosed about the densification processes. The lengths and diameters of the pellets were measured based on EN 16,127 [31] and the moisture content was measured according to ISO 18134-2 [32]. The pellet density was calculated based on the pellet weight and volume, which were measured using a laboratory balance and a caliper, respectively, for 5 randomly chosen pellets. To increase the accuracy of the pellet density results, the two ends of the pellets were polished using sandpaper resulting in a cylindrical shape with a known volume. The properties of the materials are shown in Table 1.

Table 1. Properties of the materials used in this study (pellet diameter and pellet density are the mean of 5 repetitions and the \pm show the standard deviation).

\begin{tabular}{cccccc}
\hline Sample & $\begin{array}{c}\text { Diameter } \\
\mathbf{( m m )}\end{array}$ & $\begin{array}{c}\text { Length } \\
\mathbf{( m m )}\end{array}$ & $\begin{array}{c}\text { Length/Diameter } \\
\text { Ratio } \mathbf{( - )}\end{array}$ & $\begin{array}{c}\text { Moisture } \\
\mathbf{( \% )}\end{array}$ & $\begin{array}{c}\text { Pellet Density } \\
\mathbf{( k g \cdot \mathbf { m } ^ { - 3 } )}\end{array}$ \\
\hline Sawdust & $12.49 \pm 0.15$ & $10.00-46.30$ & $0.80-3.71$ & 7.7 & $1150 \pm 37$ \\
\hline Raw miscanthus & $6.10 \pm 0.03$ & $5.00-40.00$ & $0.82-6.56$ & 4.5 & $1320 \pm 64$ \\
\hline Torrefied miscanthus & $6.00 \pm 0.08$ & $4.00-41.70$ & $0.64-6.95$ & 2.9 & $1109 \pm 22$ \\
\hline Torrefied poplar & $8.09 \pm 0.07$ & $5.50-65.90$ & $0.68-8.15$ & 7.9 & $1126 \pm 62$ \\
\hline Torrefied mixed wood & $6.02 \pm 0.04$ & $4.10-47.40$ & $0.68-7.87$ & 9.7 & $1304 \pm 40$ \\
\hline
\end{tabular}

\subsection{Methods}

\subsubsection{Determination of the Mechanical Durability}

The mechanical durability was measured using the tumbling can method, based on ISO 17831-1 [6]. According to this standard, around $500 \mathrm{~g}$ of the sample material should be selected using the European standard CEN/TS 14778 and sieved using a round holes screen size of $3.15 \mathrm{~mm}$. Then, $500 \pm 10 \mathrm{~g}$ of the material should be weighed and placed in the tumbling can. This is a steel box with a baffle attached diagonally to one wall of the cube. Once the material has been placed in the can, it is rotated at a speed of $50 \mathrm{rpm}$ for $10 \mathrm{~min}$ in order to reach a total of 500 rotations. The sample should then be sieved using the same sieve mesh and weighed again. The mechanical durability value is calculated using Equation (1):

$$
\text { Mechanical durability }=\frac{m_{2}}{m_{1}} \times 100
$$


where $m_{1}$ is the mass of sieved particles before the mechanical durability test and $m_{2}$ is the mass of the particles remaining on the sieve after the test. Each test is duplicated using two representative test samples and the reported mechanical durability value is the mean of these results.

To study the effect of PLD on mechanical durability, different test cases were considered to fully understand the breakage pattern and the mechanism of fines and dust generation. The test cases are defined as follows:

- $\quad$ Test case 1: Pellets with different length distributions.

- $\quad$ Test case 2: Pellets under different durability test conditions.

- Test case 3: Non-torrefied and torrefied pellets of the same origin.

In the first test case, pellets of sawdust, torrefied mixed wood, torrefied poplar, and raw Miscanthus were classified on visual inspection according to their lengths into four different categories relating to their length distributions and then their actual lengths were characterized using the image processing tool described in Section 2.2.2. Note that pellets of different size categories were directly chosen from the total batch as-received, and thus, there was no pre-processing for the pellets. The objective was to investigate the effect of PLD on the mechanical durability values. Category 1 consisted of pellets shorter than $15 \mathrm{~mm}$, category 2 of pellets between 15 and $30 \mathrm{~mm}$, category 3 of pellets longer than $30 \mathrm{~mm}$, and category 4 consisted of a random sample of pellet lengths, as shown in Figure 1. This random-sized sample was taken as the reference case.

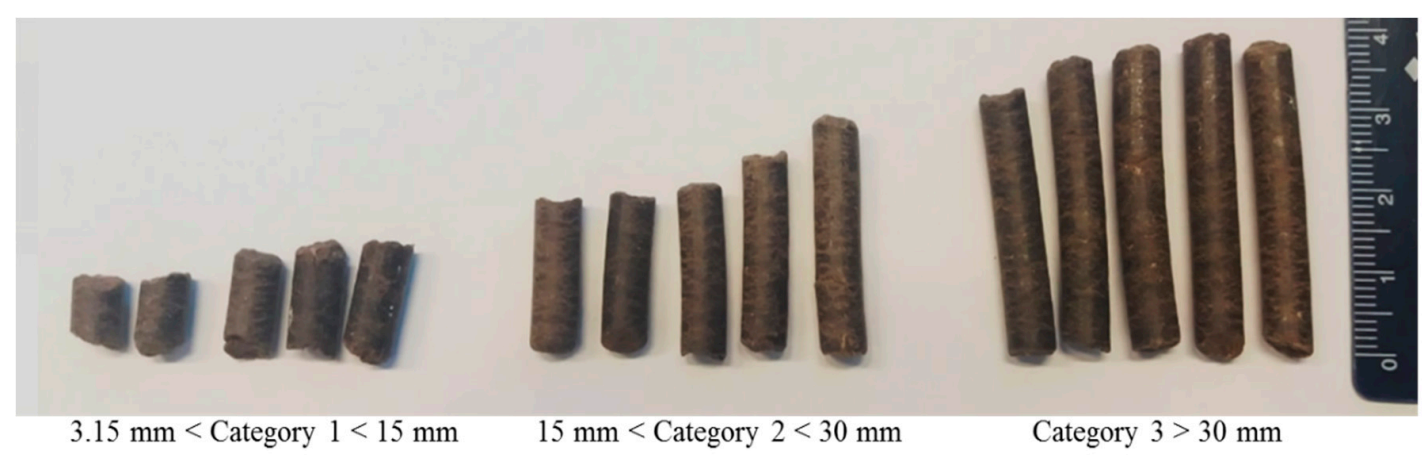

Figure 1. Samples of different categories of torrefied mixed wood pellets.

The second test case was designed to identify the critical pellet breaking time during tumbling and the effect of tumbling time on the mechanical durability values. Here, category 3 of the torrefied mixed wood and category 2 of the raw Miscanthus and categories 1 to 3 of sawdust pellets were selected in a same way as explained in the first test case. For torrefied mixed wood, the mechanical durability test was executed every $2.5 \mathrm{~min}$ up to a total mechanical durability time of $10 \mathrm{~min}$. For raw Miscanthus and sawdust, continuous full mechanical durability tests were performed three and four times respectively.

The third test case was executed to study the effect of torrefaction on the mechanical durability of biomass pellets with different length distributions. Due to the low availability of torrefied Miscanthus, categories 1 and 4 were examined here. In order to better understand the effect of torrefaction on the material's strength, individual compression tests were executed as well as the mechanical durability test. Pellets were subjected to uniaxial and diametrical compression tests by means of a compression device (Instron 5500R) at a constant compression rate of $1 \mathrm{~mm} \mathrm{~min}^{-1}$. For the uniaxial compression test, the ends of the pellets were sandpapered so that they could stand vertically on the lower plate with a uniform force distribution over the pellet ends. For diametrical compression, the pellets were placed lengthwise on the lower plate and compressed. Five pellets with different lengths were used for each test while the force and displacement were recorded. The stress-strain $(\sigma-\varepsilon)$ values were calculated using Equations (2) and (3) for the uniaxial compression and Equations (4) and (5) for diametrical compression [23]. 


$$
\begin{gathered}
\sigma_{a}=\frac{F}{\pi r^{2}} \\
\varepsilon_{a}=\frac{l_{0}-l}{l_{0}} \\
\sigma_{d}=\frac{F}{r l} \\
\varepsilon_{d}=\frac{d_{0}-d}{d_{0}}
\end{gathered}
$$

where $F$ is the force $(\mathrm{N}), r$ is the pellet radius $(\mathrm{mm}), l_{0}$ is the initial pellet length, $l$ is the length displacement $(\mathrm{mm}), d_{0}$ is the initial pellet diameter $(\mathrm{mm})$ and $d$ is the diameter displacement $(\mathrm{mm})$.

\subsubsection{Determination of the PLD}

As the primary goal of this study was to investigate the influence of the length on the mechanical durability characteristics of biomass pellets, the first step is to characterize the length distributions. Previous work reported the pellet length as the average length of a limited number of pellets [24,25], or a typical pellet length without mentioning the method and number of pellets to be tested [33,34]. Measuring the pellet length distribution is possible to a certain extent using standard sieving methods such as ISO 17827-1 [35]. However, the method has some drawbacks. Firstly, pellets that are longer than the sieve mesh size may pass through the sieve lengthwise, which biases the results. Secondly, the results show a distribution of pellet length for each sieve mesh size, rather than the individual pellet lengths. There is therefore a need for a more accurate, quick and easy method to automatically capture the individual pellet length. Gil et al. [36] used image processing technology to capture the size of small heterogeneous milled biomass particles (particle size $<5 \mathrm{~mm}$ ). However, there is a need for a tool to capture the length of bigger homogenous particles (biomass pellets) in a more accurate way based on the standard. For that purpose, we developed an image processing tool to capture the length of the individual pellets based on European standard EN 16127 [31] using image processing codes (extrema method, shape measurement) in MATLAB (2017b) and, therefore, the length distribution of a batch of pellets. The procedure for determining the PLD is as follows. Pellets are first placed on a light panel (to remove shadows caused by the surrounding lights above the panel). The pellets are then manually repositioned to remove any overlap. An image is then taken from above the panel and used as input information for the MATLAB codes. The tool generates a horizontal line in the centre of each pellet (dashed line in Figure 2). It then determines the end points (red circles in Figure 2) and draws vertical lines from every end point perpendicular to the horizontal line (solid lines in Figure 2). The maximum distance between these two solid lines determines the pellet length. The mass-based cumulative PLD is then calculated based on the pellet lengths and pellet density.

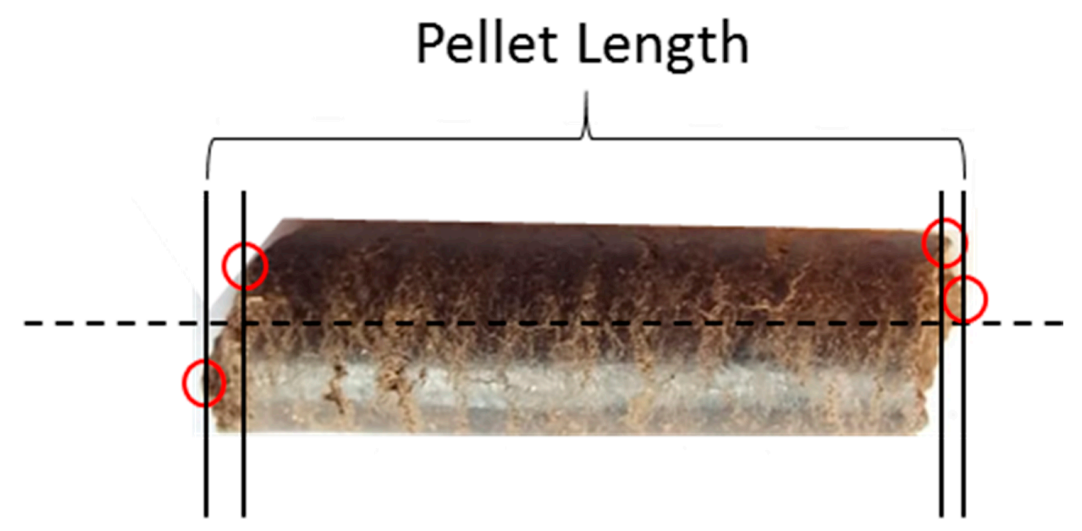

Figure 2. A two-dimensional (2D) image of a typical biomass pellet under analysis using extrema method in MATLAB (R2018b, MathWorks, Natick, MA, USA). 
Using this method, it is also possible to determine the number of pellets before and after each mechanical durability test. This helps to identify the breakage pattern during the mechanical durability test and can be used to understand the origin of fines and dust generation by providing information about the number of broken pellets and the amount of fines and dust.

\subsubsection{Validation of the Image Processing Tool}

To validate the image processing tool, the lengths of $80 \mathrm{~g}$ of pellets (test portion size according to EN 16,127 [31]) with a diameter of $6 \mathrm{~mm}$ were measured in two ways: manually using a digital caliper and automatically using the in-house tool. The tool was calibrated before use as the distance between the camera and the light panel has a big influence on the results. Therefore, a 20 euro cent coin (diameter $=22.25 \mathrm{~mm}$ ) was used to calibrate the pixel sizes based on the coin size. The results of the two measurements are given in Figure 3. As this figure shows, the developed tool was able to measure the PLD of cylindrical pellets with a very high correlation with the experimental measurements, while also capturing the total number of pellets. The $\mathrm{L}_{20}, \mathrm{~L}_{50}$ and $\mathrm{L}_{80}$ ( $\mathrm{L}_{\mathrm{x}}$ stands for the pellet length at which $\mathrm{x} \%$ by weight of the pellets have a length of $\mathrm{L}$ or lower) from the manual measurements were 13.45 , 19.99 and 24.14 respectively, and from the in-house tool 13.02, 19.48 and 25.4 respectively. The results show that the difference between the PLD measured using the tool and the manual measurements was minimal.

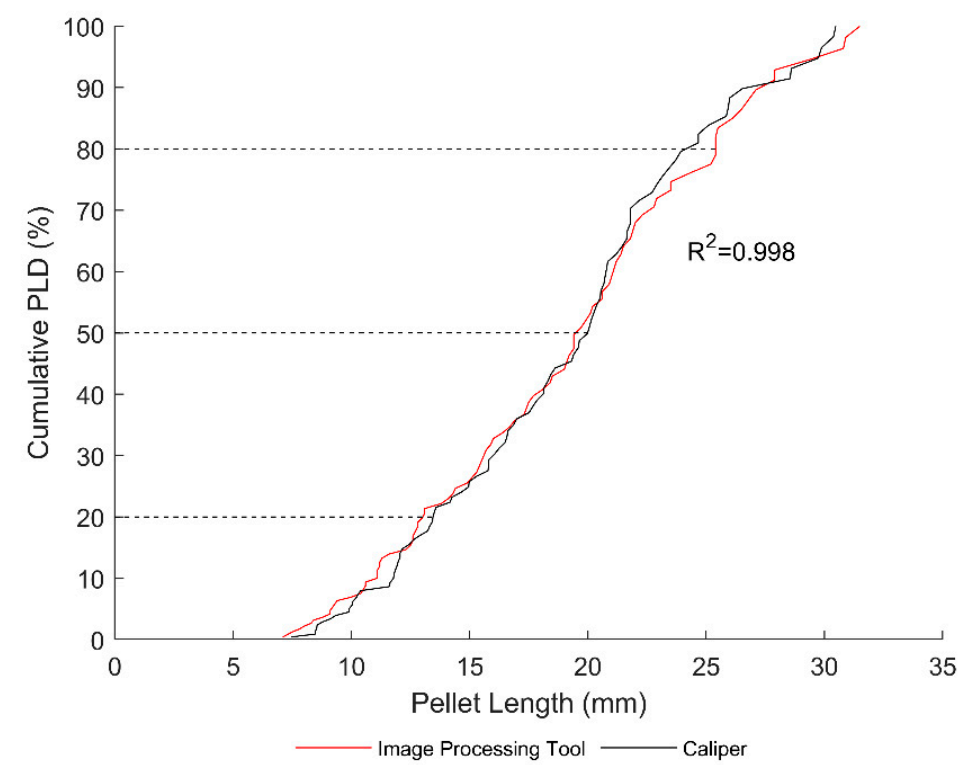

Figure 3. Pellet length distribution (PLD) measured by caliper and the in-house image processing tool.

\section{Results}

\subsection{Test Case 1}

Figure 4 shows a sample photograph of the torrefied mixed wood pellets from category 3 before and after the mechanical durability test. The mechanical durability values of various types of biomass pellets for the four PLD categories are shown in Figure 5. This clearly shows that the mechanical durability results for three of the materials (torrefied mixed wood, raw Miscanthus and torrefied poplar) depend highly on the PLD. The mechanical durability values increase with an increase in the length of the pellets. Torrefied poplar shows the highest dependency on the PLD, with a difference of $12.8 \%$ in the mechanical durability values between categories 1 and 3 , whereas for torrefied mixed wood, raw Miscanthus and sawdust pellets the value is $5.8 \%, 3.9 \%$, and $1.8 \%$ respectively. 


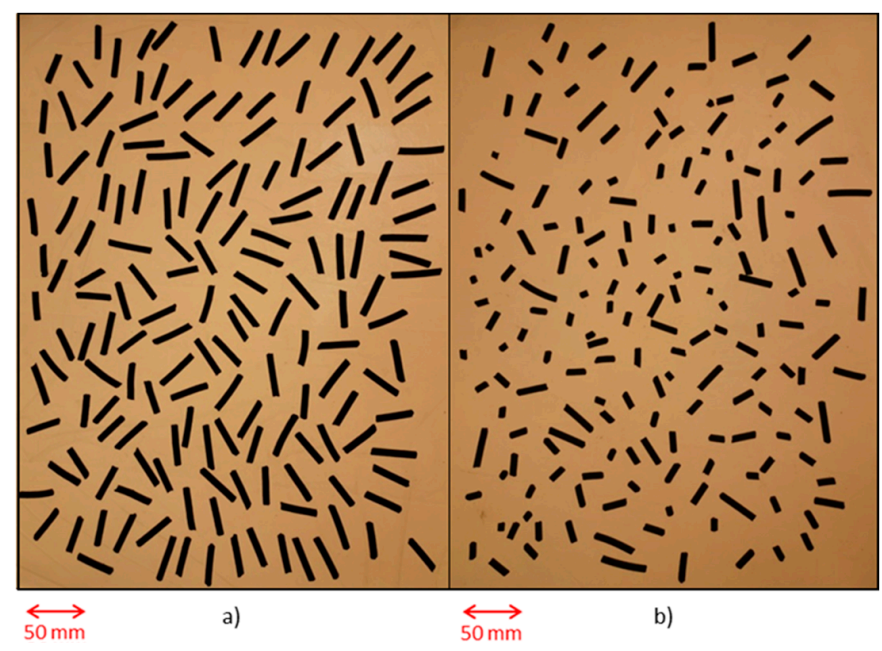

Figure 4. A sample image taken from the torrefied mixed wood pellets, (a) before and (b) after mechanical durability test.

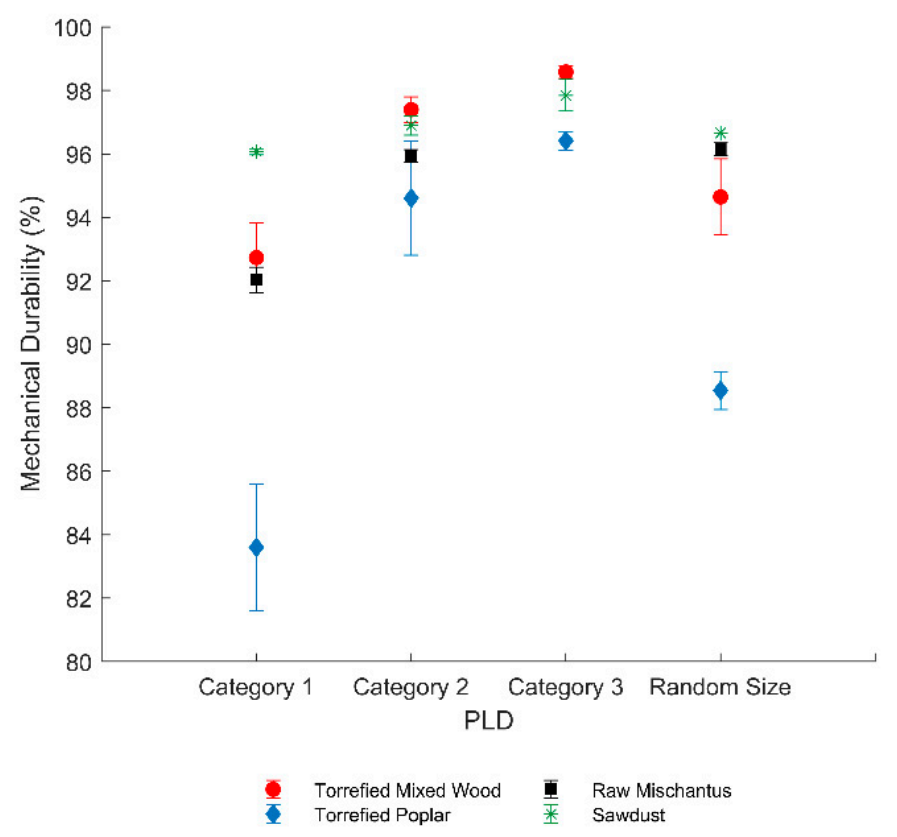

Figure 5. Mechanical durability results of different biomass pellets based on their pellet length distributions. Error bars show the standard deviation.

The PLDs before and after the mechanical durability tests are shown in Figure 6. Category 3 shows the most alteration in the PLD after the durability test, due to the fragmentation of long pellets for pellets with a diameter smaller than or equal to $8 \mathrm{~mm}$. However, Figure 5 shows that category 3 shows the highest mechanical durability values amongst all categories. Therefore, the shorter the pellets, the less breakage takes place, but the higher the probability of fines and dust generation.

The pellet diameters were also monitored by visual inspection during the experiments, and no changes were observed. A slight change in the PLD before and after the mechanical durability test for the shorter pellets (category 1) but with the same diameter values demonstrates that the fines and dust are created mostly from the edges of the pellets due to abrasive forces during the test.

Figure 5 shows a small difference between the mechanical durability of sawdust pellets in the different categories, but the trend is similar to the other types of pellets. A possible reason for this is the difference in the initial number of pellets, and consequently the number of pellet collisions and impacts inside the mechanical durability tester device. In the case of sawdust, there were 386 pellets in category 
1 and 125 pellets in category 3 before the mechanical durability test, as shown in Table 2. However, there were 2241 torrefied mixed wood pellets in category 1 and 404 in category 3 . Furthermore, due to the relatively large diameter of the sawdust pellets $(12 \mathrm{~mm})$, the length to diameter ratio was lower than for the other pellet types, resulting in a lower breakage potential during tumbling. As can be clearly seen in Figure $6 \mathrm{a}-\mathrm{c}$, pellets with a diameter of $8 \mathrm{~mm}$ and less are particularly susceptible to breakage if the length to diameter ratio is high, while no pellet breakage is seen in the sawdust pellets, even for the longer pellets (Figure 6d). Although pellet breakage does not necessarily result in more fines formation, pellet breakage does result in a higher number of pellets, which can intensify the generation of fines and dust.
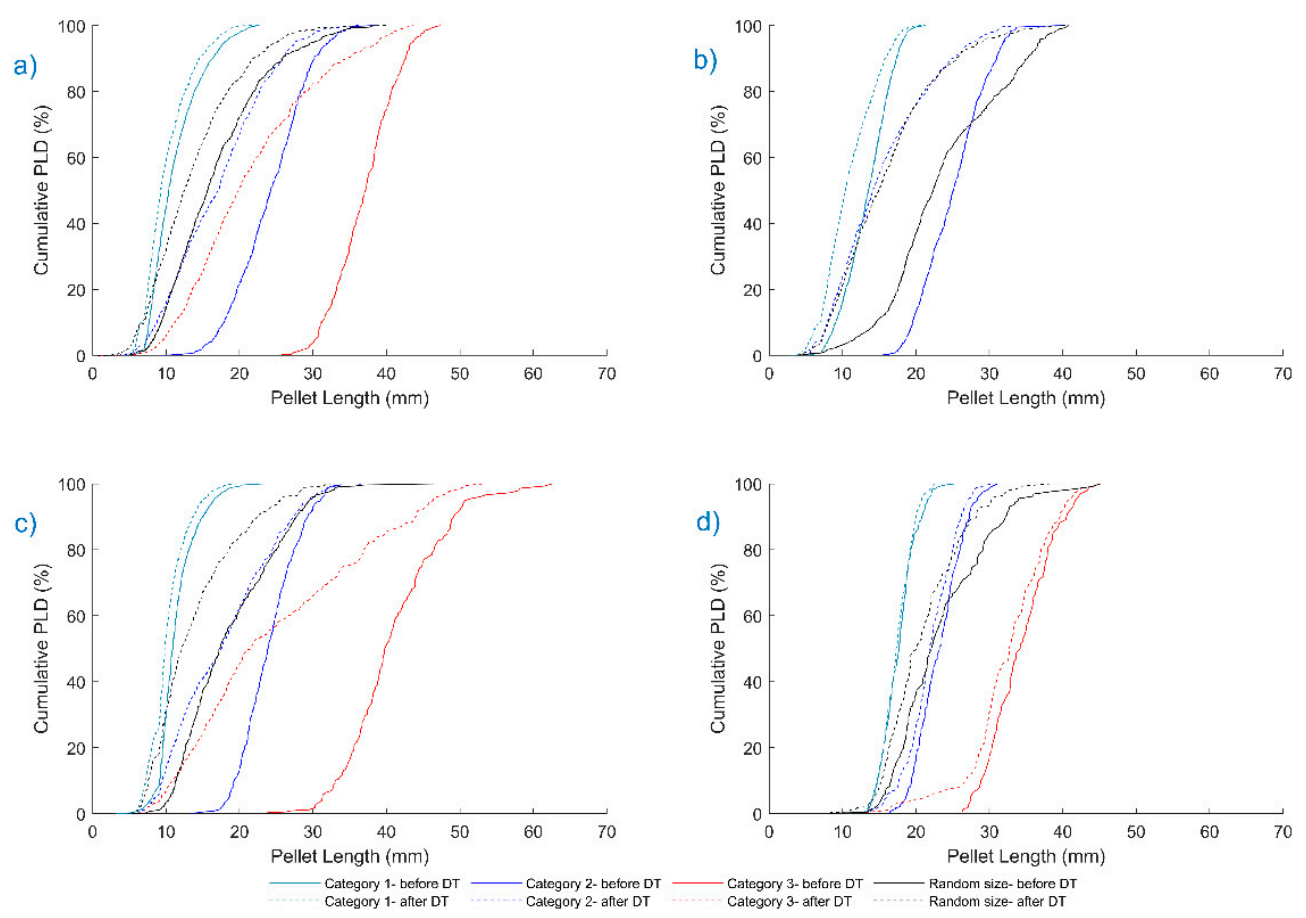

Figure 6. Pellet length distributions before and after mechanical durability tests for (a) torrefied mixed wood, (b) raw miscanthus, (c) torrefied poplar, and (d) sawdust pellets (DT: Durability test).

Table 2. Mean pellet length $\left(\mathrm{L}_{50}\right)$ and the number of pellets before and after mechanical durability test.

\begin{tabular}{ccccccc}
\hline \multirow{2}{*}{ Sample } & \multirow{2}{*}{ PLD } & \multicolumn{3}{c}{$\mathbf{L}_{\mathbf{5 0}} \mathbf{( \mathbf { m m } )}$} & \multicolumn{2}{c}{ Number of Pellets } \\
\cline { 3 - 7 } & & Before DT & After DT & \% of Change & Before DT & After DT \\
\hline \multirow{3}{*}{ Raw miscanthus } & Category 1 & 13.5 & 10.2 & 24.4 & 1329 & 1661 \\
& Category 2 & 25.1 & 14.1 & 43.8 & 612 & 1181 \\
& Random size & 22.4 & 14.9 & 33.5 & 721 & 1165 \\
Torrefied poplar & Category 1 & 10.9 & 9.8 & 10.1 & 1553 & 1498 \\
& Category 2 & 23.9 & 17.5 & 26.8 & 420 & 700 \\
& Category 3 & 39.8 & 21.6 & 45.7 & 225 & 477 \\
Torrefied & Random size & 17.2 & 12.1 & 29.6 & 730 & 955 \\
mixed wood & Category 1 & 10.4 & 9 & 13.5 & 2241 & 1785 \\
& Category 2 & 24.3 & 17.1 & 29.6 & 658 & 1094 \\
& Category 3 & 37.1 & 19.9 & 46.4 & 404 & 857 \\
Sawdust & Random size & 15.7 & 12.5 & 20.4 & 1075 & 1498 \\
& Category 1 & 17.7 & 17.3 & 2.3 & 386 & 379 \\
& Category 2 & 23.2 & 21.9 & 5.6 & 216 & 224 \\
& Category 3 & 34.2 & 32.7 & 4.4 & 125 & 136 \\
\hline
\end{tabular}

${ }^{1}$ Mechanical durability test. 
Comparing the mechanical durability results of the different categories, the lowest difference is between categories 2 and 3 . That means that pellets longer than $15 \mathrm{~mm}$ are more durable during transport and handling; in other words, they generate fewer fines and dust. To better understand the effect of PLD on mechanical durability, additional experiments were carried out on torrefied mixed wood with a mixture of PLDs. A mixture of categories 1 and 2 and a mixture of categories 2 and 3 were selected, and the results are shown in Figure 7.

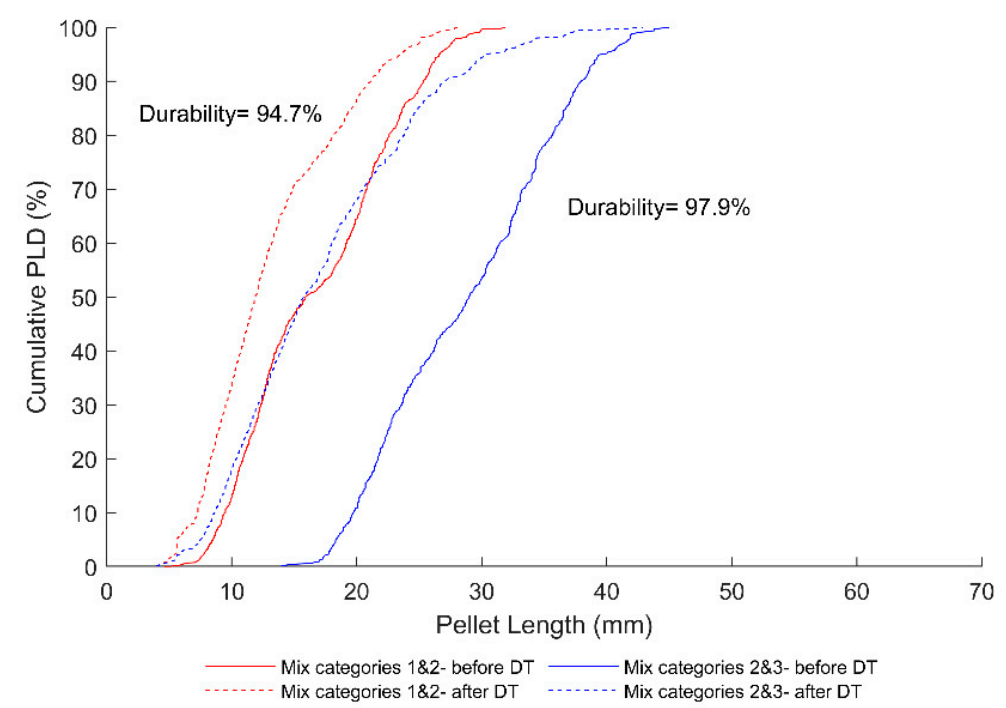

Figure 7. Pellet length distributions and mechanical durability values of torrefied mixed wood pellets: combination of categories.

The mechanical durability values of the mixtures are close to the average mechanical durability of the two corresponding categories. More interestingly, a good correlation was found between the mechanical durability results and $L_{50}$ (mean of the pellet length) with a high data fit $\left(R^{2}=0.926\right)$, as shown in Figure 8. This shows that $\mathrm{L}_{50}$ is a good indicator of the mechanical durability of biomass pellets.

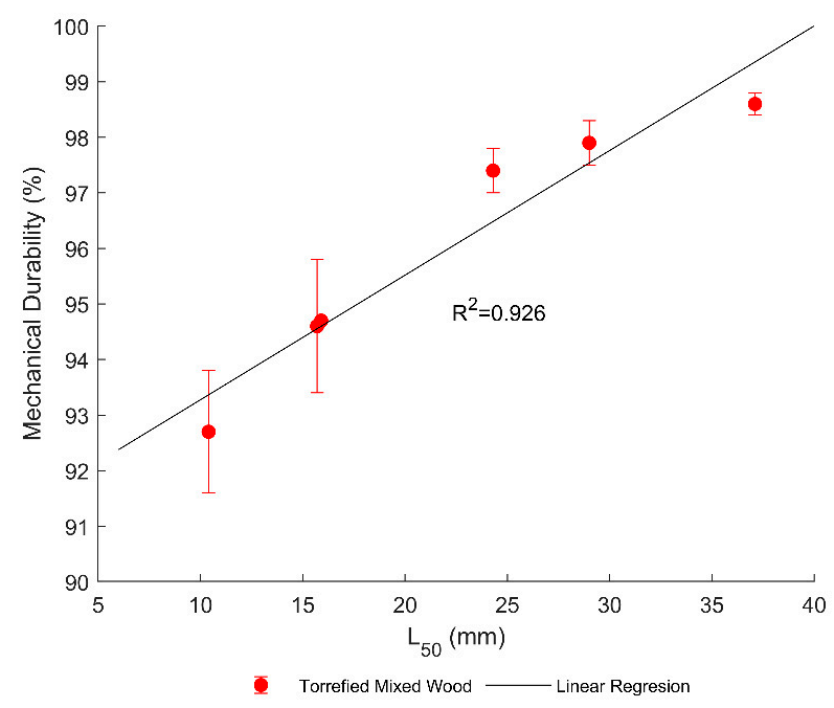

Figure 8. Mechanical durability values of torrefied mixed wood pellets versus the $\mathrm{L}_{50}$ of various length distributions. Error bars show the standard deviation.

Figure 9 shows the mechanical durability values versus the PLD intervals and $\mathrm{L}_{50}$ for each category. It shows that the mechanical durability values correlate with $\mathrm{L}_{50}$ for every type of biomass material. 


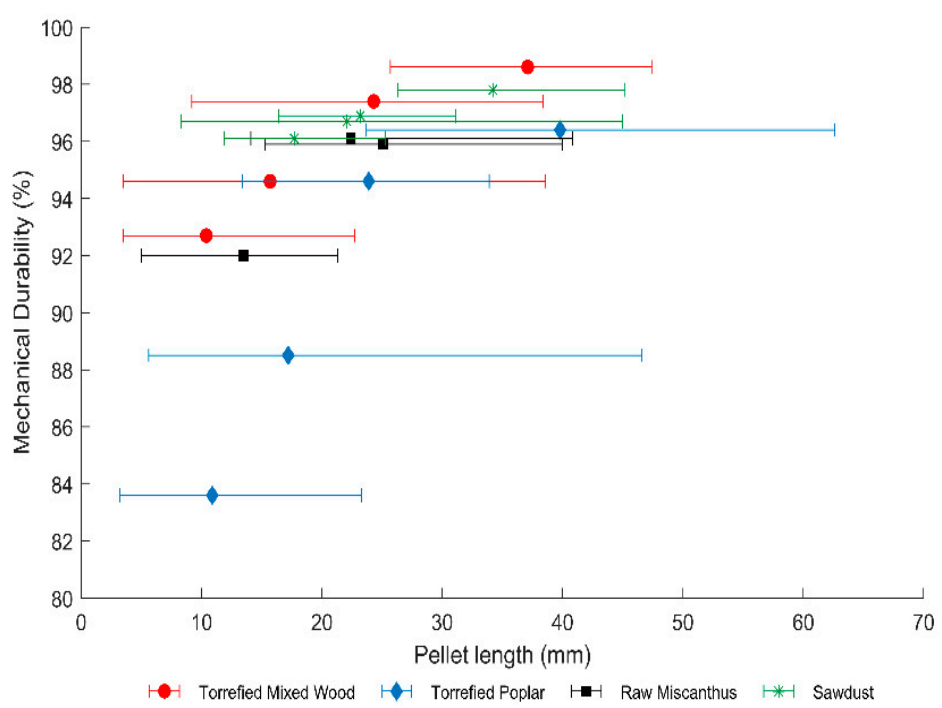

Figure 9. Mechanical durability value versus pellet length distribution intervals before mechanical durability test (solid markers show the $\mathrm{L}_{50}$ ).

\subsection{Test Case 2}

In this test case, the total mechanical durability test time for torrefied mixed wood pellets was divided into four equal time intervals: $2.5 \mathrm{~min}, 5 \mathrm{~min}, 7.5 \mathrm{~min}$, and $10 \mathrm{~min}$. For the other materials, the mechanical durability test was performed more than once. As can be seen in Figure 10a, the mechanical durability value was almost the same for torrefied mixed wood in the different time intervals, with a slightly lower value in the $2.5 \mathrm{~min}$ interval, while most breakage also took place in this interval. The slightly lower mechanical durability value was probably due to the release of dust particles due to fragmentation into smaller particles.
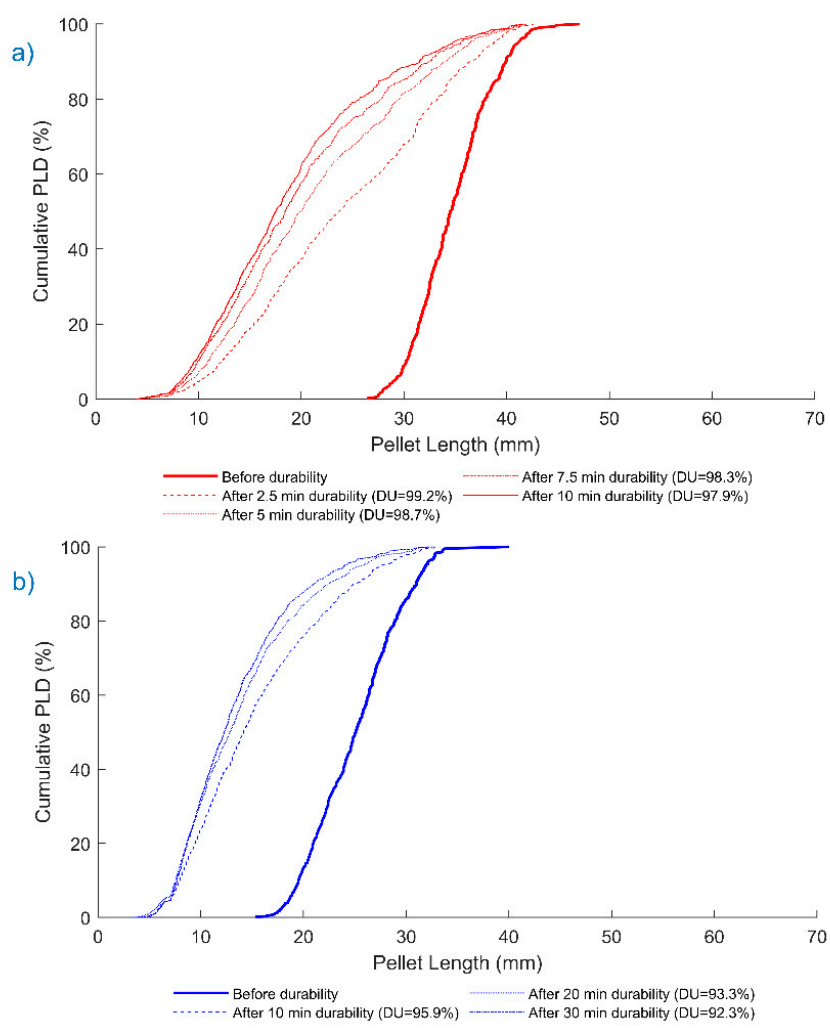

Figure 10. Pellet length distributions of (a) torrefied mixed wood and (b) raw miscanthus before and after different mechanical durability tests (DU: mechanical durability). 
For the raw Miscanthus and sawdust pellets, the mechanical durability value was lowest in the first test and became constant or even increased in the next tests, as shown in Figures 10b and 11. As the number of pellets was almost the same in the next tumbling steps, we conclude that the mechanical durability values stabilize over time, probably because the areas in the pellets with a high potential to generate fines and dust materials (weak points) release most of this early on during the mechanical durability test. We can also conclude that a sample that has already been used for mechanical durability testing should never be used again for the same purpose, since the sample has already lost the areas with high potential for fines generation.

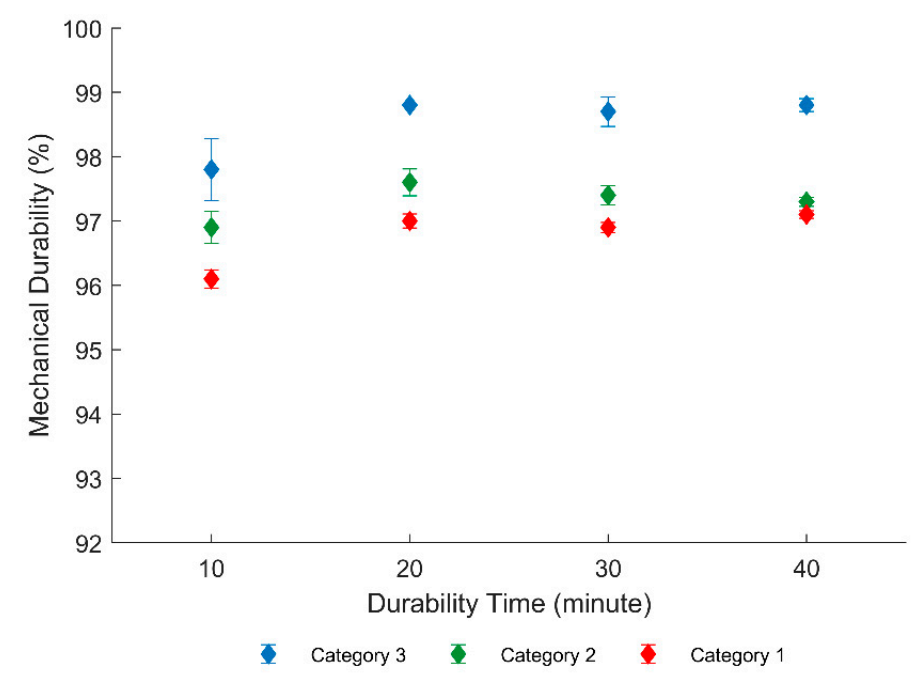

Figure 11. Mechanical durability values of sawdust pellets after several mechanical durability tests. Error bars show the standard deviation.

Assuming the mechanical durability test simulates the real forces acting on the pellets during large-scale transportation, fines and dust production is highest in the first steps and additional handling steps generate less fines and dust. This requires additional research.

\subsection{Test Case 3}

In this test case, we studied the effect of torrefaction on the mechanical durability values of biomass pellets. Due to the limited amount of available torrefied materials, only two categories were considered for this test case. Although it is reported that the torrefaction process improves the grindability of biomass materials [27], the results in Figure 12 show that torrefaction in this study has a negligible effect on the mechanical durability of pelletized materials. The obtained mechanical durability values depend more on the $\mathrm{L}_{50}$ than the torrefaction process.

We would like to point out that, despite the same mechanical durability values between the torrefied and non-torrefied Miscanthus pellets, the individual pellet strength in a compression test might be different because abrasive forces play a key role in pellet degradation in a mechanical durability test and the amount of generated dust is linked to the surface properties rather than internal pellet strength. To support this statement, we tested individual pellet strengths using compression tests. The maximum stress at failure and the corresponding strain values are presented in Table 3 . Based on the results, it is clear that the compression strengths of the raw pellets are higher than those of torrefied pellets. 


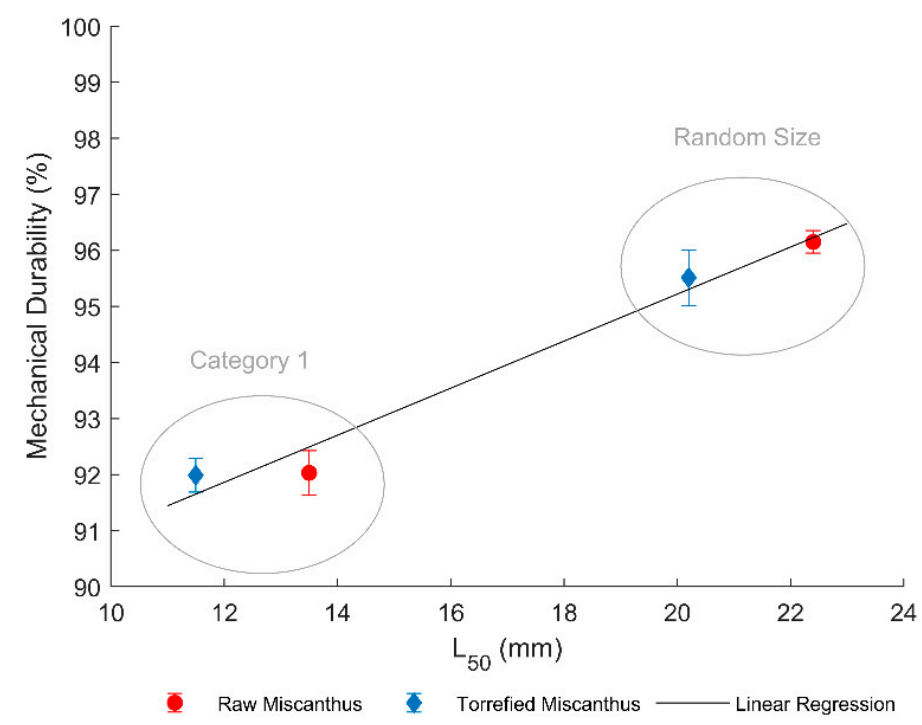

Figure 12. Mechanical durability values of raw and torrefied miscanthus pellets. Error bars show the standard deviation.

Table 3. Maximum stress and strain at failure for uniaxial and diametrical compression tests of raw and torrefied Miscanthus.

\begin{tabular}{cccccccccc}
\hline & \multicolumn{3}{c}{ Uniaxial Compression } & \multicolumn{3}{c}{ Diametrical Compression } \\
\cline { 2 - 9 } Sample No. & \multicolumn{3}{c}{ Raw Miscanthus } & $\begin{array}{c}\text { Torrefied } \\
\text { Miscanthus }\end{array}$ & Raw Miscanthus & \multicolumn{1}{c}{$\begin{array}{c}\text { Torrefied } \\
\text { Miscanthus }\end{array}$} \\
\cline { 2 - 10 } & $\sigma_{a} \mathbf{( M P a )}$ & $\varepsilon_{a}(-)$ & $\sigma_{a} \mathbf{( M P a )}$ & $\varepsilon_{a}(-)$ & $\sigma_{d} \mathbf{( M P a )}$ & $\varepsilon_{d}(-)$ & $\sigma_{d}(\mathbf{M P a})$ & $\varepsilon_{d}(-)$ \\
\hline$\mu$ & 17.64 & 0.05 & 13.43 & 0.08 & 16.04 & 0.07 & 9.95 & 0.10 \\
Standard deviation & 0.66 & 0.01 & 1.44 & 0.02 & 2.64 & 0.01 & 2.84 & 0.02 \\
\hline
\end{tabular}

\section{Discussion}

According to the literature, the mechanical strength of biomass pellets depends on pellet type characterizations such as the biomass origin (composition), the pre-treatment process and densification process specifications. However, once the pellets have been made, the pellet strength remains constant unless a significant change in environmental conditions such as temperature and relative humidity occurs. On the other hand, fines generation (particles $<3.15 \mathrm{~mm}$ ) as expressed by mechanical durability might change due to the effect of PLD; an effect that has not yet been addressed in the literature. This study shows that the mechanical durability values of biomass pellets depend on the PLD. This dependency is probably due to the number of pellets per unit mass, which determines the number of pellet-pellet and pellet-container collisions.

Thomas [37] showed in his study that pellet breakage occurs in two ways: through attrition and fragmentation, as shown in Figure 13. Therefore, in this study, fragmentation is the main breakage mechanism for longer pellets, while abrasion is more common for shorter pellets.

As well as the number of collisions affecting the mechanical durability results, the device geometry specifications may also play a role in mechanical durability results. In a tumbling can device, the shortest and longest possible travel distances for a pellet are $97 \mathrm{~mm}$ and $442.3 \mathrm{~mm}$ respectively. This means that, for a short pellet with a length of $10 \mathrm{~mm}$, the lowest and highest pellet to geometry ratio is around 1:10 and 1:44, while for a longer pellet of $40 \mathrm{~mm}$ they are 1:2.5 and 1:11. Thus, it could be expected that the longer pellets experience fewer impacts as they pass shorter distance from one side to the other side of the device. Moreover, due to the baffle in the middle of the device, the pellet flow inside the equipment is relatively chaotic, therefore not all the pellets pass the same route during the test. Note that the longer the pellets, the higher the mass and therefore the greater the impact, when travelling the same distance 
in comparison to the shorter pellets. Summarizing, calculation of the travel distances and impact forces are complex, but the device dimensions are expected to alter the mechanical durability results.

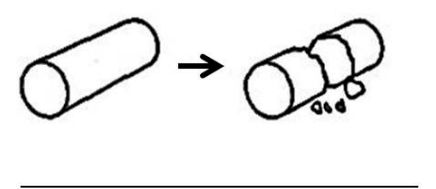

a)

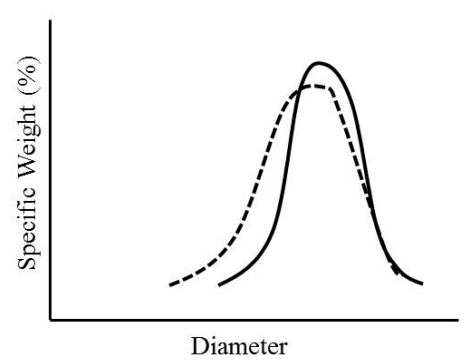

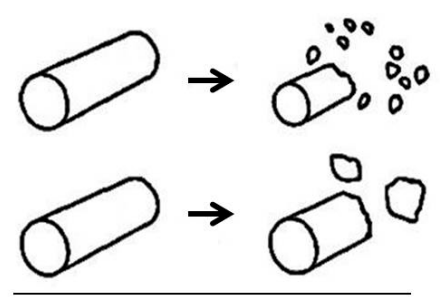

b)

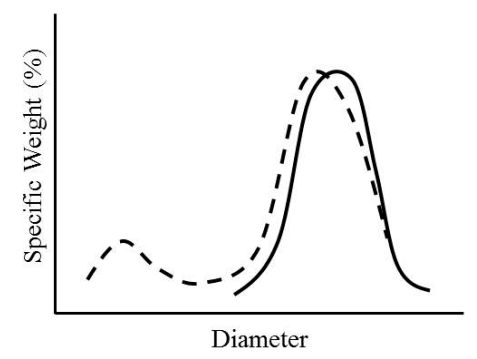

Figure 13. Two different breakage mechanisms of pellets. (a) fragmentation, (b) abrasion and their particle size distribution curves adapted from [37].

According to ISO standard 17831-1 [6], the maximum acceptable repeatability difference between the results of duplicate measurements is $2 \%$ for pellets with mechanical durability values below $97.5 \%$ and $0.4 \%$ for pellets with mechanical durability values above $97.5 \%$. However, the results of this study show that pellets of the same type with different PLDs have substantially higher differences in mechanical durability. The effect of PLD has not yet been studied in the literature, but it seems that using the same PLD for duplicate measurements may limit the differences. Moreover, this could also be the main reason for disagreement between the mechanical durability results tested at differing locations or by different users, such as buyers and sellers.

ISO standard 17831-1 was formulated to characterize the ability of biomass pellets to withstand mechanical forces during transport and handling. However, this standard suffers from a lack of information on the factors affecting the mechanical durability values. While, according to the standard, the test samples should be selected randomly, the PLD may differ from sample to sample. There is no guideline or notice in the standard about the PLD and its possible effect on the mechanical durability results. In our previous work [38], we showed that there is an urgent need for more standards or at least modification of the existing standards for the characterization of the physicochemical properties of biomass pellets. We suggest modifying ISO-17831-1 in the coming version in such a way that the PLD is reported along with the mechanical durability values.

Williams et al. [23] claimed that pellets with low mechanical durability values are not only unsuitable for transportation but also for milling. In this study, we show that choosing longer pellets tends to increase the mechanical durability value. Comparing their findings [23] with the results of this study, we can also conclude that pellets less than $15 \mathrm{~mm}$ in length are not suitable for milling processes.

Larsson et al. [30] and Rudolfsson et al. [29] pelletized torrefied materials and Manouchehrinejad and Mani [39] and Shang et al. [40] torrefied raw pellets. Irrespective of the order of the torrefaction and palletization process, they concluded that torrefaction negatively affects the mechanical durability characteristics of different commercially produced biomass pellets. In none of the studies, the pellet length distribution data are disclosed, or used in their analysis. In this study, it was also observed that considering similar PLD for raw and torrefied pellets, torrefaction after pelletization does not influence the mechanical durability of miscanthus pellets. It is likely that the difference between the mechanical durability of commercially produced torrefied and non-torrefied pellets (densified under the same 
conditions) is due to three factors: torrefaction severity, torrefaction process sequence, and PLD. Changing the torrefaction severity might lead to a difference in PLD, which in turn significantly affects mechanical durability as shown in this paper. Future studies may focus on this interdependence, i.e., the effect of torrefaction on mechanical durability before and after densification including the PLD effect.

Although the effect of PLD should be tested for other types of mechanical durability measurement methods, the same results are expected since decreasing the pellet length per unit mass increases the number of collisions. This results in a higher pellet degradation rate as demonstrated in this paper.

\section{Conclusions}

This paper is, to the best of our knowledge, the first to study the effect of pellet length on the mechanical durability characteristics of biomass pellets according to ISO standard 17831-1 [6]. Using an image processing tool, we developed a methodology to measure the individual pellet lengths of groups of particles quickly and accurately, and were able to compare the PLD before and after the tumbling can test. The conclusions of this study are as follows:

- Regardless of the origin, pelletization process characteristics and pre-treatment processes, the tendency of biomass pellets to generate fines and dust (particles passing through $3.15 \mathrm{~mm}$ sieve holes) strongly depends on the pellet length.

- The lower the pellet length per unit mass, the higher the number of pellets and, therefore, the more collisions in the tumbling can that result in a higher fines content and thus lower mechanical durability. This is confirmed for all five tested materials.

- The length to diameter ratio can affect the mechanical durability results of different PLDs. A higher length to diameter ratio decreases the difference in mechanical durability values between all PLD categories.

- The observed breakage mechanism of biomass pellets is either fragmentation (breakage into smaller pellets) or abrasion. In this study, we show that most fines and dust in a tumbling can method are generated due to abrasion and not fragmentation.

- In this study, the effect of torrefaction was studied using a single torrefied pellet type (torrefied Miscanthus), and the mechanical durability characteristic was compared to a white pellet (raw Miscanthus). For the torrefied Miscanthus, the torrefaction process was performed after pellet production. For this specific pellet, the torrefaction process was not an influencing factor in the mechanical durability characteristics of Miscanthus pellets. For a better understanding of this result, the role of the torrefaction process conditions such as time and temperature, the process sequence and PLD should be further investigated by testing a wide range of raw and torrefied pellets.

Based on the findings of this study, we highly recommend differentiating in future versions of ISO 17831-1 between the PLD categories (or the $\mathrm{L}_{50}$ ) when reporting the mechanical durability results.

Author Contributions: Conceptualization, H.G.; Data curation, H.G.; Formal analysis, H.G.; Methodology, H.G.; Supervision, W.D.J. and D.L.S.; Writing-Original draft, H.G.; Writing—Review \& Editing, H.G., W.D.J., and D.L.S. All authors have read and agreed to the published version of the manuscript.

Funding: This work was financially supported by the Top Consortium for Knowledge and Innovation for the Biobased Economy under grant number BBE-1713, Biomassa pellets: Degradatie tijdens transport en handling.

Acknowledgments: The authors would like to thank the laboratory technicians of the Maritime and Transport Technology department of TU Delft, Ed Stok and Freek Brakel, for their help with setting up the mechanical durability tester. We would also like to thank Arno Janssen from the Energy Research Centre of the Netherlands (ECN) for providing some of the biomass pellets.

Conflicts of Interest: The funders had no role in the design of the study; in the collection, analyses, or interpretation of data; in the writing of the manuscript, or in the decision to publish the results. 


\section{References}

1. Calderón, C.; Gauthier, G.; Jossart, J.-M. Bioenergy Europe Statistical Report 2019—Key Findings; European Association Bioenergy Europe: Brussels, Belgium, 2019.

2. Hedlund, F.H.; Astad, J.; Nichols, J. Inherent hazards, poor reporting and limited learning in the solid biomass energy sector: A case study of a wheel loader igniting wood dust, leading to fatal explosion at wood pellet manufacturer. Biomass Bioenergy 2014, 66, 450-459. [CrossRef]

3. Kaliyan, N.; Morey, R.V. Factors affecting strength and durability of densified biomass products. Biomass Bioenergy 2009, 33, 337-359. [CrossRef]

4. ISO 16559. Solid Biofuels- Terminology, Definitions and Descriptions; ISO: Geneva, Switzerland, 2014.

5. Temmerman, M.; Rabier, F.; Jensen, P.D.; Hartmann, H.; Böhm, T. Comparative study of durability test methods for pellets and briquettes. Biomass Bioenergy 2006, 30, 964-972. [CrossRef]

6. ISO 17831-1. Solid Biofuels-Determination of Mechanical Durability of Pellets and Briquettes-Part 1: Pellets; ISO: Geneva, Switzerland, 2015.

7. Riva, L.; Surup, G.R.; Buø, T.V.; Nielsen, H.K. A study of densified biochar as carbon source in the silicon and ferrosilicon production. Energy 2019, 181, 985-996. [CrossRef]

8. Fernández-Puratich, H.; Hernández, D.; Arce, V.L. Characterization and cost savings of pellets fabricated from Zea mays waste from corn mills combined with Pinus radiata. Renew. Energy 2017, 114, 448-454.

9. Miranda, M.T.; Sepúlveda, F.J.; Arranz, J.I.; Montero, I.; Rojas, C.V. Analysis of pelletizing from corn cob waste. J. Environ. Manag. 2018, 228, 303-311. [CrossRef]

10. Tang, Y.; Chandra, R.P.; Sokhansanj, S.; Saddler, J.N. The Role of Biomass Composition and Steam Treatment on Durability of Pellets. Bioenergy Res. 2018, 11,341-350. [CrossRef]

11. Mohammadi Ghasem Abadi, M.H.; Moravej, H.; Shivazad, M.; Karimi Torshizi, M.A.; Kim, W.K. Effect of different types and levels of fat addition and pellet binders on physical pellet quality of broiler feeds. Poult. Sci. 2019, 98, 4745-4754. [CrossRef] [PubMed]

12. Matúš, M.; Križan, P.; Šooš, L'.; Beniak, J. The effect of papermaking sludge as an additive to biomass pellets on the fi nal quality of the fuel. Fuel 2018, 219, 196-204. [CrossRef]

13. Tumuluru, J.S. Pelleting of Pine and Switchgrass Blends: Effect of Process Variables and Blend Ratio on the Pellet Quality and Energy Consumption. Energies 2019, 12, 1198. [CrossRef]

14. Dyjakon, A.; Noszczyk, T. The influence of freezing temperature storage on the mechanical durability of commercial pellets from biomass. Energies 2019, 12, 2627. [CrossRef]

15. Gilvari, H.; Cutz, L.; Tiringer, U.; Mol, A.; de Jong, W.; Schott, D.L. The Effect of Environmental Conditions on the Degradation Behavior of Biomass Pellets. Polymers 2020, 12, 970. [CrossRef]

16. SS 187120. Biofuels and Peat-Fuel Pellets; Classification-Swedish Standards Institution: Stockholm, Sweden, 1998.

17. DIN 51731. Testing of Solid Fuels. Compressed Untreated Wood. Requirements and Testing-Deutsches Institut für Normung, Berlin, Germany; German National Standard: Berlin, Germany, 1996.

18. DIN EN 15270. Pellet Burners for Small Heating Boilers. Definitions, Requirements, Testing, Marking; Deutsches Institut für Normung: Berlin, Germany, 2007.

19. CTI-R 04/5. Recommendation: Solid Biofuels. Pellet Characterization for Energetic Purposes; Milan, Italy, 2004.

20. ÖNORM, M. 7135: Compressed Wood or Compressed Bark in Natural State, Pellets and Briquettes, Requirements and Test Specifications; Osterreichisches Normungsinstitut: Vienna, Austria, 2000.

21. ISO17225-2. Solid Biofuels-Fuel Specifications and Classes_Part 2: Graded Wood Pellets; ISO: Geneva, Switzerland, 2014.

22. Larsson, S.H.; Samuelsson, R. Prediction of ISO 17831-1: 2015 mechanical biofuel pellet durability from single pellet characterization. Fuel Process. Technol. 2017, 163, 8-15. [CrossRef]

23. Williams, O.; Taylor, S.; Lester, E.; Kingman, S.; Giddings, D.; Eastwick, C. Applicability of mechanical tests for biomass pellet characterisation for bioenergy applications. Materials 2018, 11, 1329. [CrossRef]

24. Chico-Santamarta, L.; Chaney, K.; Godwin, R.J.; White, D.R.; Humphries, A.C. Physical quality changes during the storage of canola (Brassica napus L.) straw pellets. Appl. Energy 2012, 95, 220-226. [CrossRef]

25. Serrano, C.; Monedero, E.; Lapuerta, M.; Portero, H. Effect of moisture content, particle size and pine addition on quality parameters of barley straw pellets. Fuel Process. Technol. 2011, 92, 699-706. [CrossRef]

26. Bourgeois, J.P.; Doat, J. Torrefied wood from temperate and tropical species. Advantages and prospects. In Bioenergy 84. Proceedings of Conference 15-21 June 1984, Goteborg, Sweden. Volume III. Biomass Conversion; Elsevier Applied Science Publishers: London, UK, 1984; pp. 153-159. 
27. Arias, B.; Pevida, C.; Fermoso, J.; Plaza, M.G.; Rubiera, F.; Pis, J.J. Influence of torrefaction on the grindability and reactivity of woody biomass. Fuel Process. Technol. 2008, 89, 169-175. [CrossRef]

28. Stelte, W.; Clemons, C.; Holm, J.K.; Sanadi, A.R.; Ahrenfeldt, J.; Shang, L.; Henriksen, U.B. Pelletizing properties of torrefied spruce. Biomass Bioenergy 2011, 35, 4690-4698. [CrossRef]

29. Rudolfsson, M.; Borén, E.; Pommer, L.; Nordin, A.; Lestander, T.A. Combined effects of torrefaction and pelletization parameters on the quality of pellets produced from torrefied biomass. Appl. Energy 2017, 191, 414-424. [CrossRef]

30. Larsson, S.H.; Rudolfsson, M.; Nordwaeger, M.; Olofsson, I.; Samuelsson, R. Effects of moisture content, torrefaction temperature, and die temperature in pilot scale pelletizing of torrefied Norway spruce. Appl. Energy 2013, 102, 827-832. [CrossRef]

31. EN 16127. Solid Biofuels—Determination of Length and Diameter of Pellets; European Committee for Standardization: Brussels, Belgium, 2012.

32. ISO 18134-2. Solid Biofuels—Determination of Moisture Content-Oven Dry Method_Part 2: Total Moisture-Simplified Method; ISO: Geneva, Switzerland, 2017.

33. Graham, S.; Eastwick, C.; Snape, C.; Quick, W. Mechanical degradation of biomass wood pellets during long term stockpile storage. Fuel Process. Technol. 2017, 160, 143-151. [CrossRef]

34. Graham, S.; Ogunfayo, I.; Hall, M.R.; Snape, C.; Quick, W.; Weatherstone, S.; Eastwick, C. Changes in mechanical properties of wood pellets during artificial degradation in a laboratory environment. Fuel Process. Technol. 2016, 148, 395-402. [CrossRef]

35. ISO 17827-1. Solid Biofuels-Determination of Particle Size Distribution for Uncompressed Fuels-Part: Oscillating Screen Method Using Sieves with Apertures of $3.15 \mathrm{~mm}$ and Above; ISO: Geneva, Switzerland, 2016.

36. Gil, M.; Teruel, E.; Arauzo, I. Analysis of standard sieving method for milled biomass through image processing. Effects of particle shape and size for poplar and corn stover. Fuel 2014, 116, 328-340. [CrossRef]

37. Thomas, M. Physical Quality of Pelleted Feed: A Feed Model Study; Thomas: Wageningen, The Netherlands, 1998.

38. Gilvari, H.; de Jong, W.; Schott, D.L. Quality parameters relevant for densification of bio-materials: Measuring methods and affecting factors-A review. Biomass Bioenergy 2019, 120, 117-134. [CrossRef]

39. Manouchehrinejad, M.; Mani, S. Torrefaction after pelletization (TAP): Analysis of torrefied pellet quality and co-products. Biomass Bioenergy 2018, 118, 93-104. [CrossRef]

40. Shang, L.; Nielsen, N.P.; Dahl, J.; Stelte, W.; Ahrenfeldt, J.; Holm, J.K.; Thomsen, T.; Henriksen, U.B. Quality effects caused by torrefaction of pellets made from Scots pine. Fuel Process. Technol. 2012, 101, $23-28$. [CrossRef]

(C) 2020 by the authors. Licensee MDPI, Basel, Switzerland. This article is an open access article distributed under the terms and conditions of the Creative Commons Attribution (CC BY) license (http://creativecommons.org/licenses/by/4.0/). 